\title{
Case Report \\ Successful Nonoperative Management of Spontaneous Splenic Hematoma and Hemoperitoneum due to CMV Infection
}

\author{
Georgios Lianos, Eleftheria Ignatiadou, Christina Bali, \\ Haralampos Harissis, and Christos Katsios \\ Department of Surgery, University Hospital of Ioannina, St. Niarchou Avenue, 45110 Ioannina, Greece \\ Correspondence should be addressed to Georgios Lianos, georgiolianos@yahoo.gr
}

Received 21 October 2012; Accepted 19 November 2012

Academic Editors: O. I. Giouleme and T. Hirata

Copyright (C) 2012 Georgios Lianos et al. This is an open access article distributed under the Creative Commons Attribution License, which permits unrestricted use, distribution, and reproduction in any medium, provided the original work is properly cited.

Introduction. Spontaneous splenic hematoma or splenic rupture due to CMV infection in immunocompetent adults is rare and life-threatening. Case Report. Herein we report a rare case of spontaneous splenic hematoma and hemoperitoneum due to CMV infection in a 23-year-old Caucasian male in whom conservative management was successful. Conclusion. Spontaneous splenic hematoma and spontaneous splenic rupture are extremely rare conditions during primary CMV infection. Though rare, they must be always considered by the operating surgeon, because any misinterpretation may result in unfavorable outcomes.

\section{Introduction}

Human cytomegalovirus is a member of the herpes family of viruses and undergoes latency after primary infection $[1,2]$. The primary infection is diagnosed by a strongly positive CMV IgM antibody test result or CMV IgG seroconversion. Spontaneous splenic rupture or subcapsular splenic hematoma is really an uncommon condition in primary CMV infection [3]. The management of these complications has been a matter of debate during the last years [4]. Although splenectomy is the appropriate treatment for hemodynamically unstable patients, it seems that nonoperative management in selected patients is nowadays considered the gold standard of care $[5,6]$.

\section{Case Report}

A 23-year-old Caucasian male was admitted to the emergency department of our hospital due to severe left upper quadrant abdominal pain. His medical history was free, and no recent trauma was reported. Clinical examination revealed no pyrexia, heart rate at 90 per minute, and normal blood pressure. Upon physical examination, upper abdominal tenderness was revealed. On auscultation, abdominal sounds were present. Rectal examination showed an empty rectum.

The emergent laboratory tests revealed the following: WBC $24350 / \mathrm{mm}^{3}$, hemoglobin $14,2 \mathrm{~g} / \mathrm{dl}$, platelets $278000 / \mathrm{mm}^{3}$, c-reactive protein $17 \mathrm{mg} / \mathrm{dl}$, Tbil $1,9 \mathrm{mg} / \mathrm{dl}$, Dbil 0,28 , ast $27 \mathrm{IU} / \mathrm{L}$, alt $42 \mathrm{IU} / \mathrm{L}$, and creatinine and electrolytes were normal. An abdominal ultrasound showed splenomegaly $(17,27 \times 8,7 \mathrm{~cm})$ and free fluid in the left iliac fossa and in pelvis (Figures 1 and 2). The urgent abdominal computerized tomography (CT) confirmed an enlarged spleen and showed a splenic hematoma with the presence of free fluid in the paracolic gutters and pelvis. There was a hyperdense component within the free fluid, indicating hemoperitoneum (Figure 3).

The patient was managed conservatively because of his hemodynamic stability. The diagnosis of primary CMV infection was made with positive IgM anti-CMV antibodies. He was under close monitoring and surgical supervision. He was hemodynamically stable all the time, and two weeks later a new CT of the abdomen was arranged. CT demonstrated the same splenic hematoma and a little resolution of the peritoneal effusion (Figure 4). After a period of prolonged bed rest (twenty days), the patient was discharged from the hospital with the advice to avoid 


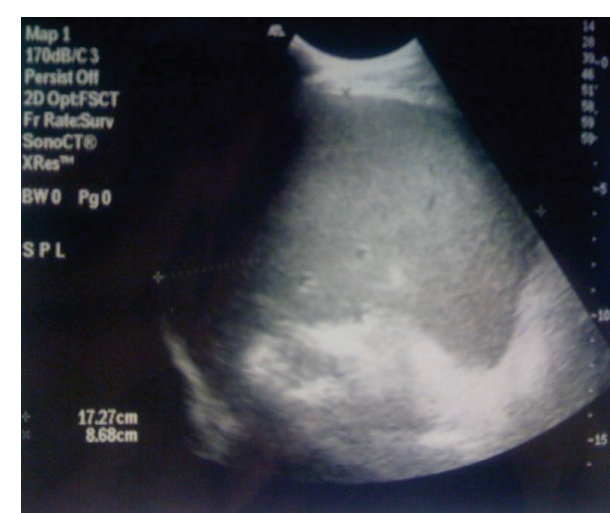

Figure 1: Abdominal ultrasound showed splenomegaly $(17,27 \times$ $8,7 \mathrm{~cm}$ ) and free fluid in the left iliac fossa.

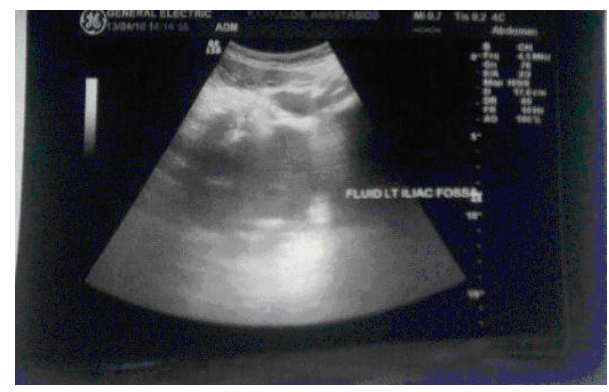

Figure 2: Abdominal ultrasound showed splenomegaly $(17,27 \times$ $8,7 \mathrm{~cm}$ ) and free fluid in the left iliac fossa.

extreme sports and activities. Five months later, followup with ultrasound examinations showed progressive resolution of the splenic hematoma and complete resolution of the peritoneal effusion.

\section{Discussion}

It is reported that spontaneous splenic rupture is extremely rare $(0,1 \%-0,5 \%)[7,8]$. Clinical presentation includes severe upper abdominal pain with guarding and tenderness. Crucial for prompt surgical intervention is the early diagnosis of splenic rupture. The pathologies which lead to spontaneous splenic hematoma and splenic rupture include hematological malignancies (acute leukemia, chronic leukemia), splenic tumors and metastases, infections (Epstein-Barr virus, malaria, and CMV), amyloidosis, druginduced disorders, and disorders in pregnancy [9].

The mechanism for the spontaneous hematoma and the splenic rupture is not yet fully clear. However, it seems that it consists in increased intrasplenic tension caused by cellular hyperplasia and vascular occlusion caused by reticular endothelial hyperplasia. This leads to subcapsular hemorrhage, formation of subcapsular hematoma, and rupture of the splenic capsule [10].

Spontaneous subcapsular splenic hematoma with hemoperitoneum, splenic contusions-lacerations, and complete spontaneous splenic rupture are rare and life-threatening

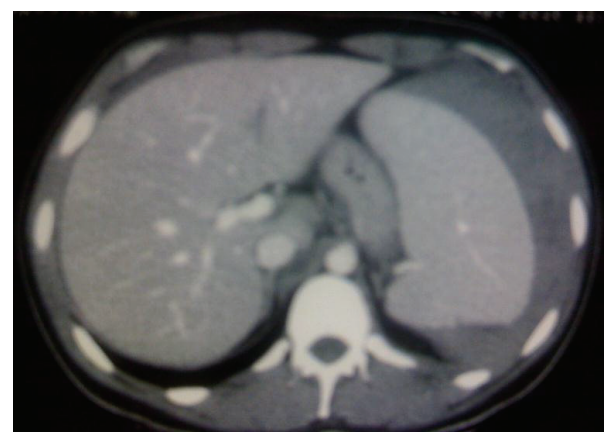

FIGURE 3: Urgent abdominal computerized tomography (CT) showed an enlarged spleen and splenic hematoma with the presence of free intraperitoneal fluid.

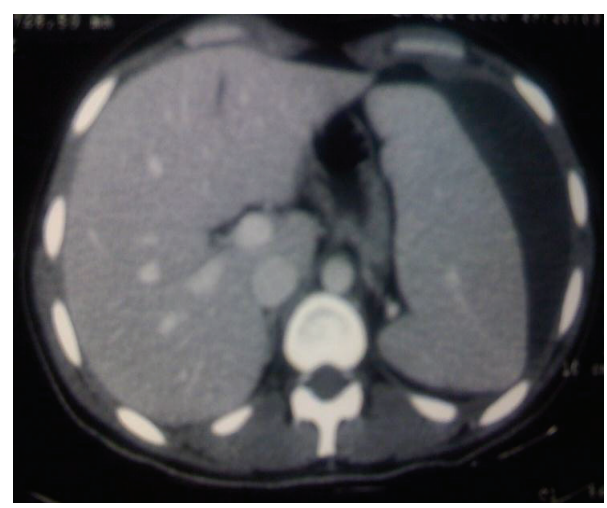

FIGURE 4: CT, two weeks after patient's admission, showed the same splenic hematoma.

complications of primary CMV infection in young immunocompetent adults. To our knowledge, only few reports on splenic "surgical" involvement during primary CMV infection treated conservatively have been published to date.

In order to explore this, we conducted a PubMed search using the key words "splenic hematoma," "CMV infection," "conservative management," and "splenic rupture." We found only five cases, including our case, of "surgical" splenic involvement during primary CMV infection in immunocompetent adults. These patients were treated successfully with nonoperative management $[11,12]$ (Table 1).

In case of hemodynamic instability, it is obvious that splenectomy is the treatment of choice. When, however, the patient is hemodynamically stable, as in our case, the non-operative management is a safe option with the patient under close monitoring and surgical supervision [13-15]. Recent studies showed that splenectomy dogma tends to be supplanted by conservative management. Conservative treatment can be successful if appropriate criteria and a close monitoring are applied in selected hemodynamically stable patients. Splenectomy should be reserved only for patients with uncontrollable rupture and hemodynamic instability [16, 17]. 
TABLE 1: Successful conservative management in case of splenic rupture or splenic hematoma due to CMV infection in young immunocompetent individuals.

\begin{tabular}{|c|c|c|c|c|c|}
\hline Reference & Sex & Age & Comorbidities & CMV diagnosis & Spleen lesions \\
\hline (1) Losada et al., 1997 [11] & Female & 30 & - & $\begin{array}{l}\text { (i) Viruria } \\
\text { (ii) IgM }\end{array}$ & $\begin{array}{l}\text { Subcapsular } \\
\text { Hematoma }\end{array}$ \\
\hline (2) Bellaiche et al., 1998 [12] & Male & 22 & - & $\begin{array}{l}\text { (i) Seroconversion } \\
\text { (ii) IgM }\end{array}$ & $\begin{array}{c}\text { Splenomegaly } \\
\text { Hemoperitoneum }\end{array}$ \\
\hline (3) Maillard et al., 2007 [4] & Male & 29 & Pyruvate Kinase deficiency & $\begin{array}{c}\text { (i) IgM } \\
\text { (ii) Positive blood PCR } \\
\text { (iii) pp65 antigenemia }\end{array}$ & Partial splenic rupture \\
\hline (4) Maillard et al., 2007 [4] & Female & 22 & Iron deficiency anemia & $\begin{array}{l}\text { (i) IgM, seroconversion } \\
\text { (ii) Positive blood PCR } \\
\text { (iii) pp65 antigenemia }\end{array}$ & $\begin{array}{l}\text { Hemoperitoneum } \\
\text { Splenic contusions }\end{array}$ \\
\hline (5) Our case (Lianos et al.) & Male & 23 & - & (i) $\operatorname{IgM}$ & $\begin{array}{l}\text { Hemoperitoneum } \\
\text { Splenic hematoma }\end{array}$ \\
\hline
\end{tabular}

\section{Conclusion}

In conclusion, the diagnosis of splenic hematoma or splenic rupture due to CMV infection in young immunocompetent individuals can be very difficult and requires a high suspicion and a lot of awareness on the part of the surgeon. These conditions must be always considered when dealing with left upper abdominal pain in young immunocompetent adults in order to prevent the dramatic consequences of a missed diagnosis.

\section{Conflict of Interests}

The authors declare that they have no conflict of interests.

\section{Ethical Approval}

Written informed consent was obtained from the patient for publication of this paper. A copy of the written consent is available for review by the Editor-in-Chief of this journal.

\section{Authors' Contribution}

All authors approved the final paper form.

\section{References}

[1] Y. Kano and T. Shiohara, "Current understanding of cytomegalovirus infection in immunocompetent individuals," Journal of Dermatological Science, vol. 22, no. 3, pp. 196-204, 2000.

[2] G. Just-Nübling, S. Korn, B. Ludwig, C. Stephan, H. W. Doerr, and W. Preiser, "Primary cytomegalovirus infection in an outpatient setting-laboratory markers and clinical aspects," Infection, vol. 31, no. 5, pp. 318-323, 2003.

[3] A. M. Rogues, M. Dupon, V. Cales et al., "Spontaneous splenic rupture: an uncommon complication of cytomegalovirus infection," Journal of Infection, vol. 29, no. 1, pp. 83-85, 1994.

[4] N. Maillard, M. Koenig, S. Pillet, M. Cuilleron, and P. Cathébras, "Spontaneous splenic rupture in primary cytomegalovirus infection," Presse Medicale, vol. 36, no. 6 I, pp. 874877, 2007.
[5] J. G. Schuler and H. Filtzer, "Spontaneous splenic rupture: the role of nonoperative management," Archives of Surgery, vol. 130, no. 6, pp. 662-665, 1995.

[6] V. Velanovich and D. Tapper, "Decision analysis in children with blunt splenic trauma: the effects of observation, splenorrhaphy, or splenectomy on quality-adjusted life expectancy," Journal of Pediatric Surgery, vol. 28, no. 2, pp. 179-185, 1993.

[7] S. J. Rhee, Y. Sheena, and C. Imber, "Spontaneous rupture of the spleen: a rare but important differential of an acute abdomen," American Journal of Emergency Medicine, vol. 26, no. 6, pp. 733.e5-733.e6, 2008.

[8] P. Renzulli, A. Hostettler, A. M. Schoepfer, B. Gloor, and D. Candinas, "Systematic review of atraumatic splenic rupture," British Journal of Surgery, vol. 96, no. 10, pp. 1114-1121, 2009.

[9] E. Gedik, S. Girgin, M. Aldemir, C. Keles, M. C. Tuncer, and A. Aktas, "Non-traumatic splenic rupture: report of seven cases and review of the literature," World Journal of Gastroenterology, vol. 14, no. 43, pp. 6711-6716, 2008.

[10] Y. Yagmur, I. H. Kara, M. Aldemir, H. Buyukbayram, I. H. Tacyildiz, and C. Keles, "Spontaneous rupture of malarial spleen: two case reports and review of literature," Critical Care, vol. 4, no. 5, pp. 309-313, 2000.

[11] I. Losada, A. Ramos, F. Portero et al., "Hematoma subcapsulae esplenico asociado con CMV en un patiente immunocompetente," Enfermedades Infecciosas y Microbiología Clínica, vol. 15, pp. 121-122, 1997.

[12] G. Bellaiche, E. Habib, F. Baledent et al., "Hemoperitoine par rupture spontanee de rate: une complication exceptionnelle de la primo-infection a CMV," Gastroentérologie Clinique Et Biologique, vol. 22, pp. 107-108, 1998.

[13] M. M. Asgari and D. G. Begos, "Spontaneous splenic rupture in infectious mononucleosis: a review," Yale Journal of Biology and Medicine, vol. 70, no. 2, pp. 175-182, 1997.

[14] P. J. Duarte, M. Echavarria, A. Paparatto, and R. Cacchione, "Spontaneous spleen rupture associated with active cytomegalovirus infection," Medicina, vol. 63, no. 1, pp. 4648, 2003.

[15] R. Amathieu, L. Tual, S. Rouaghe, J. Stirnemann, O. Fain, and G. Dhonneur, "Splenic rupture associated with CMV infection: case report and review of the literature," Annales Francaises d'Anesthesie et de Reanimation, vol. 26, no. 7-8, pp. 674-676, 2007.

[16] I. Brichkov, L. Cummings, R. Fazylov, and J. H. Horovitz, "Nonoperative management of spontaneous splenic rupture in infectious mononucleosis: the role for emerging diagnostic 
and treatment modalities," American Surgeon, vol. 72, no. 5, pp. 401-404, 2006.

[17] C. Rapp, T. Debord, P. Imbert, O. Lambotte, and R. Roué, "Spontaneous splenic rupture in infectious diseases: splenectomy or conservative treatment? Report of three cases," Revue de Medecine Interne, vol. 23, no. 1, pp. 85-91, 2002. 


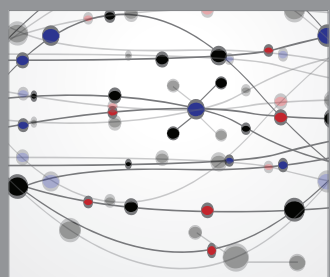

The Scientific World Journal
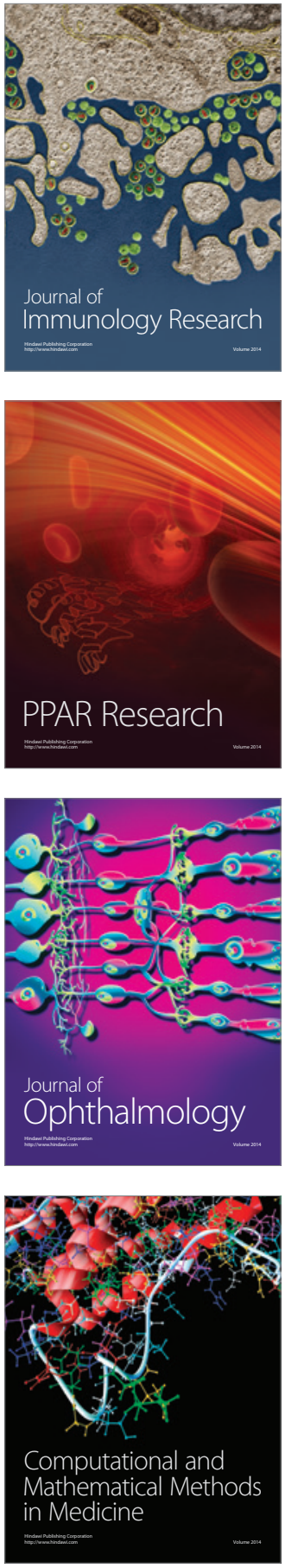

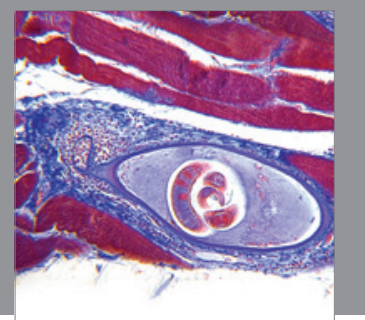

Gastroenterology

Research and Practice
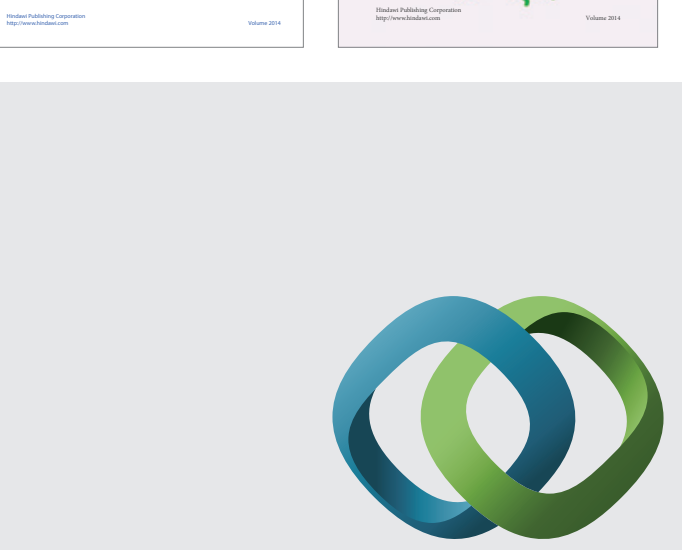

\section{Hindawi}

Submit your manuscripts at

http://www.hindawi.com
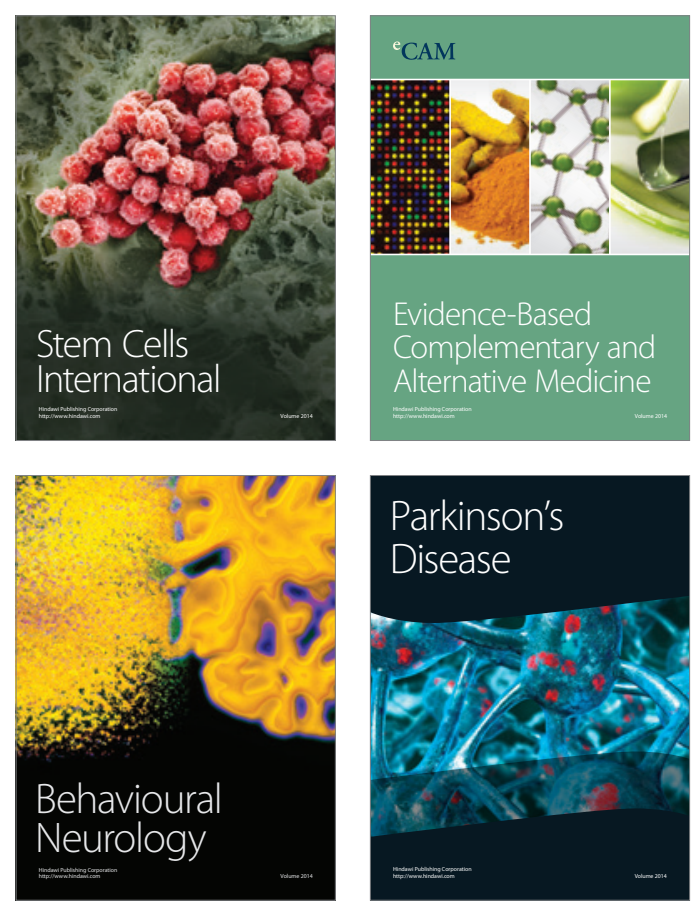

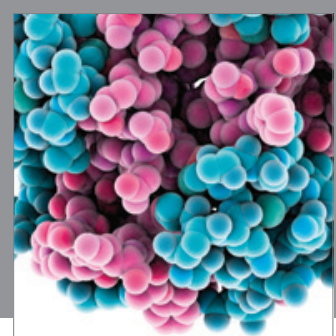

Journal of
Diabetes Research

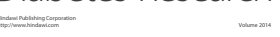

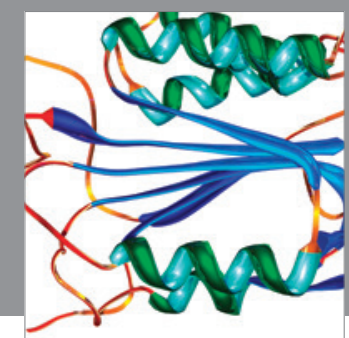

Disease Markers
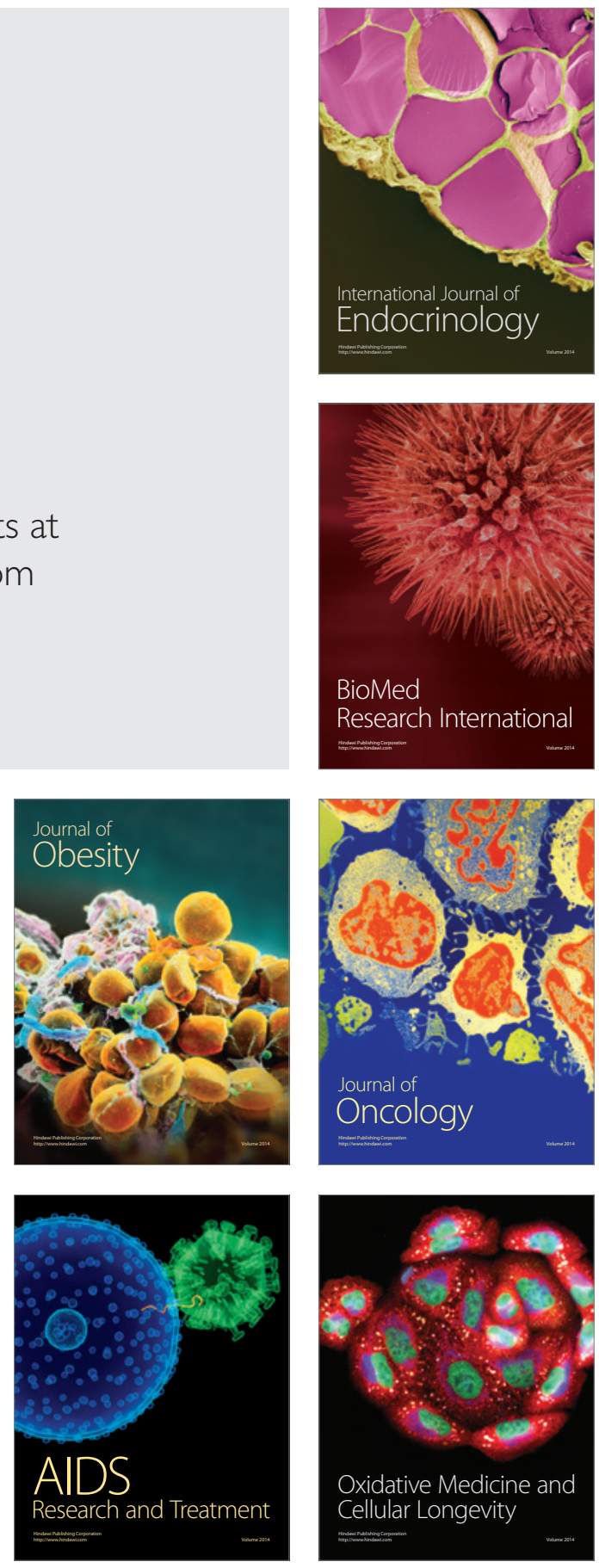